\title{
Niveljalkaisten biodiversiteetti mansikkaviljelmillä
}

\author{
Tuomo Tuovinen ja Timo Tolonen \\ MTT, kasvintuotannon tutkimus, 31600 Jokioinen, \\ tuomo.tuovinen@mtt.fi, timo.tolonen@mtt.fi
}

\section{Tiivistelmä}

Niveljalkaisten biodiversiteettia mansikalla tarkastellaan monipuolisen eliöyhteisön tarjoamien kasvinsuojelullisten hyötyjen näkökulmasta. Selvitimme tavanomaisilla ja luonnonmukaisilla mansikkaviljelyksillä esiintyvää lajistoa ja niiden runsaussuhteita vuosina 1995-2000 kerätystä materiaalista. Yhteensä 36 viljelykseltä eri menetelmin kasvustosta ja maan pinnalta kerätystä aineistosta määritettiin 615 hyönteislajia tai sukua ja 135 hämähäkkilajia tai sukua. Suurin osa lajeista arvioitiin viljelykasvin kannalta satunnaisiksi vierailijoiksi tai lajeiksi, jotka liittyvät rikkakasveihin tai rivivälikasvustoon. Viljelykasvin kannalta hyödyllisiksi arvioitiin noin 70 hyönteislajia tai sukua. Luonnonmukaisilla viljelyksillä sekä lajien että yksilöiden määrä oli suurempi kuin tavanomaisilla viljelyksillä, mutta viljelysten välinen vaihtelu oli suuri.

\section{Johdanto}

Viljelysten biodiversiteetin ylläpidolla voidaan tavoitella hyötyä maan kasvukunnon tai viljelykasvin tuoton kannalta. Kasvinsuojelun näkökulmasta runsas ja monilajinen eliöyhteisö viljelyksellä voi hillitä viljelykasvia ravintona käyttävien eliöiden runsastumista (Easterbrook 1997, Sunderland ja Samu 2000). Yksivuotisessa viljelyssä 'hyötylajien' ilmaantuminen ja runsastuminen tapahtuu kuitenkin taloudellisesti katsoen liian pitkällä viiveellä, sen sijaan monivuotiselle mansikkapellolle voi kehittyä monipuolinen niveljalkaisten (Arthropoda) yhteisö, jonka lajeista vain osa on mansikkaa hyväksikäyttäviä kasvinsyöjiä. Verrattuna tavanomaiseen peltoviljelyyn mansikkamaa on erikoislaatuinen viljely-ympäristö paitsi monivuotisuuden myös katteiden käytön ja rivivälikasvuston vuoksi. Muokattua peltoa pysyvämmän eliöyhteisön muodostuminen on mahdollista mansikalla.

Torjunta-aineiden käyttö vaikuttaa paitsi kohdelajeihin myös muihin mansikkamaan eliöihin. Suuntaus torjunta-aineiden käytön vähentämiseen ja luonnonmukaisen viljelyn kasvu on selvästi lisännyt viljelyksillä esiintyvää elämää. 'Uusien' lajien ilmestyminen ja runsastuminen voi aiheuttaa viljelijöissä epätietoisuutta hyönteisten haitallisuuden arvioinnissa. Lajirunsauden mahdollisten kasvinsuojelullisten hyötyjen arvioimiseksi on tiedettävä mitä lajeja viljelyksillä esiintyy.

Tämän tutkimuksen ensisijaisena tavoitteena oli määrittää mansikalla esiintyvä niveljalkaisten lajisto. Tässä vaiheessa on keskitytty mansikkakasvustossa esiintyviin ja maan pinnalla liikkuviin lajeihin. Tutkimuksen tavoitteena on myös tarkastella lajiston ja yksilörunsauden eroja luonnonmukaisessa ja tavanomaisessa viljelyssä ja pohtia lajirunsauden vaikutuksia kasvinsuojelun kannalta. Edelleen tavoitteena on nimetä mansikan kannalta myönteisen biodiversiteetin indikaattorilajeja tai lajiryhmiä sekä puskurilajeja, joiden esiintymisen voidaan olettaa toimivan ennaltaehkäisevästi haitallisten lajien invaasion hidastajina.

\footnotetext{
Aineisto ja menetelmät

Tutkimuksessa käytetty materiaali on koottu eri tutkimusten yhteydessä 1995-1999 kerätyistä hyönteis-, punkki- ja hämähäkkinäytteistä. Suurin osa aineistosta on peräisin vatinäytteistä (Tuovinen ja Parikka 1997), lisäksi aineistossa on lehtinäytteiden ja kuoppa-ansojen materiaalia. Näytteiden keruu on painottunut ennen mansikan kukintaa ja kukinnan aikaan, mutta joillakin viljelyksillä näytteitä on kerätty koko kasvukauden ajan. Useimmilla viljelyksillä näytteitä kerättiin 2-3 vuoden ajan. Tämän tutkimuksen tarkastelun kohteena on 26 tavanomaiselta ja 10 luonnonmukaiselta viljelykseltä kerätyt näytteet. Tavanomaisilla viljelyksillä tehtiin vuosittain 1-4 insektisidikäsittelyä, luonnonmukaisilla tiloilla joko ei lainkaan tai ainoastaan pyretriinikäsittely. Näytteistä on määritetty yhteensä yli 35000 hyönteis- ja hämähäkkiyksilöä. Tiedot on tallennettu BIOTA-tietokantaan. Kolmen samalla alueella sijaitsevan tavanomaisen ja kolmen luonnonmukaisen viljelmän lajiston runsautta verrattiin käyttäen Shannonin diversiteetti-indeksiä H' (Lambshead et al. 1983, McAleece et al. 1999).
} 


\section{Tulokset}

Tavanomaisilta ja luonnonmukaisilta viljelyksiltä kerätystä aineistosta määritettiin 615 hyönteislajia tai sukua ja 135 hämähäkkilajia tai sukua. Luonnonmukaisilla viljelyksillä (10 kpl) lajeja rekisteröitiin 540 ja tavanomaisilla viljelyksillä (26 kpl) 578 lajia. Mansikan eriasteisiksi tuholaisiksi luokiteltavia lajeja on aineistossa noin 70. Ainakin osittain hyödyllisiksi pedoiksi on arvioitu noin 130 lajia, pääasiassa kovakuoriaisia, mutta myös $\mathrm{mm}$. luteita. Loispetojen (Hymenoptera) ja hämähäkkien joukossa on runsaasti hyödyllisiä lajeja, mutta niiden merkitystä ei pystytä vielä arvioimaan, koska tiedot isäntä- tai saaliseläimistä ovat puutteellisia. Mansikalla esiintyviä petopunkkeja on määritetty 12 lajia, joista muutama on arvioitu merkittäviksi torjuntaeliöiksi. Seuraavassa yhteenvedossa keskitytään hämähäkkejä (Araneae), kovakuoriaisia (Coleoptera) ja nivelkärsäisiä (Hemiptera) koskeviin tuloksiin.

Hämähäkkejä määritettiin 129 lajia, jotka jakaantuivat 14 heimoon (Taulukko 1). Vatinäytteissä yleisimmin esiintyi luomuviljelyksillä Pardosa amentata (8\% havainnoista), Xysticus audax $(7.3 \%)$ ja Neottiura bimaculata (4.8\%), tavanomaisilla viljelyksillä Erigone atra (5.6\%), N. bimaculata (5.3 $\%)$ ja Tibellus oblongus (5.2\%). Kuoppa-ansoissa luomuviljelysten päälajit olivat Oedothorax apicatus (17.5\%), Trochosa ruricola (16.6 \%) ja Pardosa agrestis (13.4\%) ja tavanomaisilla viljelyksillä lajit T. ruricola (20.5\%), O. apicatus (16.6\%) ja Erigone dentipalpis (9.0\%).

Taulukko 1. Hämähäkkien (Araneae) jakautuminen heimoihin tavanomaisilla ja luonnonmukaisilla viljelyksillä. Yhteensä 129 määritettyä lajia (vain aikuiset yksilöt mukana).

\begin{tabular}{lllllllll}
\hline & \multicolumn{3}{c}{ Vatinäytteet $(10+26$ peltoa) } & \multicolumn{3}{c}{ Kuoppa-ansat $(1+1$ peltoa) } \\
\cline { 2 - 9 } Araneae & \multicolumn{3}{c}{ \% havainnoista } & \multicolumn{3}{c}{$\%$ lajeista } & \multicolumn{3}{c}{$\%$ havainnoista } & \% lajeista \\
Heimo & luomu & tavanom. luomu & tavanom. luomu & tavanom. luomu & tavanom. \\
\hline Lycosidae & 13 & 8.2 & 9.6 & 5.8 & 63.2 & 41.5 & 27.7 & 20.9 \\
Linyphiidae & 36.3 & 37.2 & 54.2 & 46.6 & 35.3 & 50.7 & 48.9 & 51.2 \\
Theridiidae & 19.4 & 10.6 & 10.8 & 10.7 & 0.2 & 0.5 & 4.3 & 7 \\
Thomisidae & 17.4 & 11.6 & 7.2 & 6.8 & 0.4 & 4.2 & 4.3 & 4.7 \\
Araneidae & 4.8 & 6 & 4.8 & 5.8 & 0.5 & 2 & 4.3 & 7 \\
Philodromidae & 2.7 & 8.4 & 2.4 & 4.9 & 0.1 & 0 & 2.1 & 0 \\
Dictynidae & 2.6 & 5.1 & 3.6 & 3.9 & 0 & 0 & 0 & 0 \\
Clubionidae & 2 & 1.8 & 2.4 & 2.9 & 0.2 & 0.5 & 2.1 & 4.7 \\
Salticidae & 1.1 & 1.8 & 1.2 & 4.9 & 0.1 & 0 & 2.1 & 0 \\
Tetragnathidae & 0.4 & 8.2 & 1.2 & 1.9 & 0 & 0 & 0 & 0 \\
Metidae & 0.4 & 0.6 & 2.4 & 2.9 & 0 & 0 & 0 & 0 \\
Gnaphosidae & 0 & 0.3 & 0 & 1 & 0.1 & 0.5 & 2.1 & 2.3 \\
Pisauridae & 0 & 0.1 & 0 & 1 & 0.1 & 0.1 & 2.1 & 2.3 \\
Zoridae & 0 & 0.1 & 0 & 1 & 0 & 0 & 0 & 0 \\
\hline N hav./lajit & 546 & 670 & 83 & 103 & 1253 & 848 & 47 & 43 \\
\% hav. & 44.9 & 55.1 & & & 59.6 & 40.4 & & \\
\hline
\end{tabular}

Punkkeja (Acari) mansikkamailla esiintyy noin 20 lajia, joista mansikan tuholaisina mansikkapunkki (Phytonemus pallidus) ja vihannespunkki (Tetranychus urticae). Tässä ja aikaisemmissa tutkimuksissa (1987-1999) on mansikalla löydetty yhteensä 15 petopunkkilajia (Phytoseiidae, Anystidae), joista myönteisen biodiversiteetin indikaattorilajeiksi mahdollisesti soveltuvia lajeja ovat Anthoseius rhenanus, Euseius finlandicus ja Anystis spp.

Kovakuoriaiset (Coleoptera) olivat selvästi runsaslajisin hyönteislahko. Kovakuoriaisia määritettiin yhteensä 281 lajia. Vatinäytteistä määritetyt lajit jakautuivat heimoihin taulukon 2 mukaisesti. Tavallisimmat 'tyyppilajit' tavanomaisilla ja luomuviljelyksillä olivat lähes samoja, tuholaisista hillanälvikäs (Galerucella sagittariae) ja vattukärsäkäs (Anthonomus rubi) esiintyivät yleisimmin molemmissa viljelytyypeissä. Pedoista leppäpirkkoja (Coccinellidae) esiintyi melko vähän, sen sijaan lyhytsiipislajeja (Staphylinidae) oli runsaasti. Hyödyllisiksi luokiteltuja maakiitäjäisiä (Carabidae) esiintyi 42 lajia, suurin osa kuoppa-ansoissa. Sysikiitäjäinen (Pterostichus melanarius) oli yleisin laji. 
Pistiäiset (Hymenoptera) olivat kovakuoriaisten jälkeen runsaslajisin hyönteislahko, 185 lajia tai sukua vatinäytteissä. Suuri osa on määritetty vain suvun tarkkuudella, joten kokonaislajimäärä on jonkin verran suurempi. Suurin osa pistiäisistä kuuluu parasitoideihin (alalahko Parasitica), joiden merkitys on arvioitava isäntälajien mukaan mihin tässä tutkimuksessa ei ollut mahdollisuuksia. Runsaslajisimmat heimot olivat kihopistiäiset (Ichneumonidae) ja vainopistiäiset (Braconidae).

Nivelkärsäisiä (Hemiptera) määritettiin 100 lajia, 51 kuului luteisiin (Heteroptera) ja 49 yhtäläissiipisiin (Homoptera) (Taulukko 3). Nurmiluteisiin (Miridae) kuului huomattavasti suurempi osa tavanomaisilla viljelyksillä (47.3\%) kuin luomuviljelyksiin $(25.7 \%)$. Tavallisimmat tuholaislajit kuuluvat nurmiluteisiin, tyyppilaji molemmissa viljelytyypeissä oli peltolude (Lygus rugulipennis). Nurmiluteisiin kuuluu myös petoja, joita ovat myös naskaliluteet (Nabidae) ja nokkaluteet (Anthocoridae).

Taulukko 2. Kovakuoriaisten (Coleoptera) jakautuminen heimoihin vatinäytteissä ja tyypillisimmät lajit. Yhteensä 231 määritettyä lajia.

\begin{tabular}{lllllll}
\hline & \multicolumn{2}{l}{ Luomuviljelykset \% } & \multicolumn{3}{l}{ Tavanomaiset viljelykset \% } \\
Heimo & Hav. & Lajit & Tyyppilaji & Hav. & Lajit & Tyyppilaji \\
\hline Chrysomelidae & 30 & 9 & Galerucella sagittariae & 30 & 13.4 & G. sagittariae \\
Lathridiidae & 18.5 & 4.8 & Corticarina gibbosa & 11 & 5.1 & C. gibbosa \\
Curculionidae & 10.3 & 15 & Anthonomus rubi & 14.4 & 19.1 & A. rubi \\
Brentidae & 9.5 & 6 & Apion viciae & 9.1 & 6.4 & A. viciae \\
Staphylinidae & 8.2 & 20.4 & Atheta fungi & 6.9 & 15.9 & Anthophagus caraboides \\
Cantharidae & 3.2 & 7.2 & Cantharis figurata & 9.3 & 8.9 & C. figurata \\
Cryptophagidae & 4.3 & 5.4 & Atomaria fuscata & 2.7 & 3.2 & A. fuscata \\
Coccinellidae & 2.6 & 6 & Propylaea 14-punctata & 4.6 & 5.1 & Scymnus haemorrhoidalis \\
Tenebrionidae & 2.8 & 0.6 & Lagria hirta & 2.3 & 0.6 & L. hirta \\
Carabidae & 3.2 & 7.2 & Acupalpus meridianus & 0.5 & 3.8 & - \\
Other & 5.4 & 18.6 & - & 9.3 & 19.1 & - \\
\hline N hav./lajit & 1360 & 167 & & 992 & 157 & \\
\% hav./lajit & 57.8 & 70.8 & 42.2 & 66.5 & \\
\hline
\end{tabular}

Taulukko 3. Nivelkärsäisten (Hemiptera) jakautuminen heimoihin vatinäytteissä ja tyypillisimmät lajit. Yhteensä 100 määritettyä lajia.

\begin{tabular}{lllllll}
\hline & \multicolumn{3}{l}{ Luomuviljelykset, \% } & \multicolumn{3}{l}{ Tavanomaiset viljelykset, \% } \\
Heimo & Hav. & Lajit & Tyyppilaji & Hav. & Lajit & Tyyppilaji \\
\hline Miridae & 25.7 & 16 & Lygus rugulipennis & 47.3 & 22.4 & L. rugulipennis \\
Nabidae & 17 & 8 & Nabis brevis & 8.3 & 5.9 & Nabis flavomarginatus \\
Cicadellidae & 11.2 & 20 & Empoasca flavescens & 9.8 & 16.5 & E. flavescens \\
Aphididae & 14 & 6 & Acyrthosiphon pisum & 3.2 & 3.5 & - \\
Delphacidae & 9.6 & 12 & A. albosignata & 4.9 & 14.1 & Javesella discolor \\
Cercopidae & 4.1 & 2 & Philaenus spumarius & 7.7 & 2.4 & P. spumarius \\
Lygaeidae & 6.4 & 8 & Trapezonotus arenarius & 4.1 & 8.2 & T. arenarius \\
Psyllidae & 2.1 & 8 & Aphalara pauli & 4.5 & 4.7 & Cacopsylla peregrina \\
Pentatomidae & 4.3 & 8 & Dolycoris baccarum & 2.9 & 9.4 & D. baccarum \\
Anthocoridae & 3.4 & 4 & Anthocoris nemorum & 3.4 & 2.4 & A. nemorum \\
Other & 2.2 & 8 & - & 3.9 & 10.6 & - \\
\hline N hav./lajit & 534 & 50 & & 875 & 85 & \\
\% hav./lajit & 37.9 & 50 & & 62.1 & 85 & \\
\hline
\end{tabular}

Luonnonmukaisen ja tavanomaisen viljelyn erojen selvittämiseksi aineistosta valittiin samaa aluetta edustavat tilaparit, joilla näytteiden otto ja viljelyolosuhteet vastasivat mahdollisimman hyvin toisiaan. Kolmen tilaparin vatinäytetuloksia verrattiin diversiteetti-indeksin avulla. Lajien 
yksilömäärät jakautuivat tasaisemmin tähän valituilla tavanomaisilla viljelyksillä kuin luonnonmukaisilla viljelyksillä ('equitability index', Shannon J) (Taulukko 4).

Muista hyönteislahkoista kaksisiipisiä (Diptera) ei määritetty lajilleen ja näytteet jakautuivat 16 heimoon. Lahkoihin perhoset (Lepidoptera), verkkosiipiset (Neuroptera), hyppyhäntäiset (Collembola), ripsiäiset (Thysanoptera) ja torakat (Blattaria) kuuluvia lajeja vatinäytteissä esiintyi vain vähän.

Taulukko 4. Niveljalkaisten lajiston biodiversiteetti kolmella luonnonmukaisella ja kolmella tavanomaisella viljelyksellä. Näytteet v. 1997.

\begin{tabular}{lllllll}
\hline & \multicolumn{3}{l}{ Luomuviljelykset } & \multicolumn{3}{c}{ Tavanomaiset viljelykset } \\
\cline { 2 - 7 } & 1 & 2 & 3 & 1 & 2 & 3 \\
\hline Näytteitä, kpl & 6 & 6 & 8 & 6 & 7 & 6 \\
Havaintoja & 545 & 300 & 159 & 67 & 54 & 50 \\
Yksilöitä & 1066 & 615 & 260 & 96 & 63 & 60 \\
Lajeja & 139 & 97 & 89 & 39 & 39 & 32 \\
Shannon H'(log10)* & 1.514 & 1.427 & 1.676 & 1.416 & 1.574 & 1.391 \\
Shannon H'max $(\log 10)$ & 2.155 & 2.004 & 1.959 & 1.602 & 1.643 & 1.531 \\
Shannon J (H'/H'max) & 0.703 & 0.712 & 0.851 & 0.884 & 0.958 & 0.909 \\
\hline
\end{tabular}

* Diversiteetti-indeksi (McAleece et al., 1999)

\section{Tulosten tarkastelu}

Näytteenottomenetelmistä johtuen aineisto ei kuvaa kattavasti lajien välisiä runsaussuhteita, mutta kasveilla esiintyvä lajisto on suhteellisen hyvin edustettu, lukuun ottamatta perhosia, joita vatinäytteeseen saadaan niukasti. Myös pistiäisten ja kaksisiipisten vatinäytteeseen tuleva osuus jää varmasti pienemmäksi kuin kovakuoriaisten, luteiden ja hämähäkkien vastaavat osuudet kasveilla esiintyvistä yksilöistä. Kuoppa-ansalla edustavin otos saadaan kovakuoriaisista.

Aineistossa oli 2.6 kertaa enemmän tavanomaisia tiloja, minkä vuoksi lajien kokonaismäärä tavanomaisilla tiloilla oli jonkin verran suurempi. Kun verrataan samanikäisiä, samalla viljelyalueella olevia luonnonmukaisia ja tavanomaisia viljelyksiä keskenään havaitaan, että luonnonmukaisesti viljeltyjen peltojen lajisto ja yksilörunsaus oli moninkertainen tavanomaisesti viljeltyihin peltoihin verrattuna. Torjunta-aineiden käyttö on epäilemättä suurin lajirunsauteen vaikuttava yksittäinen tekijä kun tarkastellaan samanikäisiä kasvustoja, mutta huomattava vaikutus on myös viljelyksen lähiympäristön kasvillisuuden laadulla ja viljelyksellä esiintyvillä rivivälikasveilla. Hyönteisten kokonaismääriin suhteutettu biodiversiteetti-indeksi ei kuitenkaan suuresti poikennut eri viljelymuotojen välillä, sen sijaan yksilöiden jakautuminen lajien välillä osoittaa että luonnonmukaisilla viljelyksillä esiintyi enemmän dominoivia lajeja kuin tavanomaisilla viljelyksillä.

Mansikalla esiintyvien haitallisten mansikkapunkin ja vihannespunkin luontaisina vihollisina esiintyvät yleisimmät petopunkit indikoivat hyvin torjunta-aineiden käyttöä. Toisaalta petopunkkien esiintymiseen vaikuttaa myös ympäristön kasvullisuus. Nämä lajit voivat toimia pellolle ilmaantuvia haitallisia punkkeja hyväksikäyttävinä puskurilajeina.

\section{Johtopäätökset}

Tutkimuksen tuottamaa tietoa voidaan käyttää hyväksi tuhoeläinten biologisen ja luontaisen torjunnan kehittämisessä. Viljelytekniikan muutosten, esim. rivivälien hoitotekniikan aiheuttamien välillisten kasvinsuojeluvaikutusten arviointi on tutkimustulosten perusteella aikaisempaa helpompaa. Pitkään kukkivien, mettä ja siitepölyä tuottavien kasvustojen merkitys viljelysten lähellä tai lohkojen sisällä myönteisen biodiversiteetin ylläpitäjänä kannattaa tutkimuksen perusteella selvittää erikseen.

\section{Kiitokset}

Tutkimus on saanut rahoitusta Maa- ja metsätalousministeriöltä, mistä lausumme kiitokset. 


\section{Kirjallisuus}

Easterbrook, M.A. 1998. The beneficial fauna of strawberry fields in south-east England. Journal of Horticultural Science \& Biotechnology 73: 137-144.

McAleece, N., Lambshead, P.J.D. \& Paterson, G.L.J. 1999. BioDiversity Pro, application published at: http:// www.nrmc.demon.uk/bdpro/top.htm.

Sunderland, K. \& F. Samu, F. 2000. Effects of agricultural diversification on the abundance, distribution, and pest control potential of spiders: a review. Entomologia Experimentalis et Applicata 95 (1):1-13.

Tuovinen, T. \& Parikka, P. 1997. Monitoring strawberry pests and disease: practical applications for decision making. Acta Horticulturae 439: 931-940. 